\title{
Fragmenting Fatherhood: The Regulation of Reproductive Technologies
}

\section{S Sheldon}

The Modern Law Review Limited 68(4) 523-553

July 2005

\author{
Post Refereed Version - Not Published Version
}

\begin{abstract}
:
Reproductive technologies offer the potential to break down parenthood into a number of constituent parts. These disruptive possibilities mean that the regulation of reproductive technologies holds important potential for study, providing a significant resource that has been little analysed with regard to fatherhood. This study attempts to remedy that lacuna through consideration of a range of recent developments in this area of English law. It reaches two general conclusions. First, while the law regulating reproductive technologies attributes great importance to fatherhood, this is rooted primarily (though not exclusively) in concerns for the symbolic importance of fathers, rather than in more practical considerations such as ensuring financial provision or a second hands-on carer for a child. Secondly, the Human Fertilisation and Embryology Act (1990) contains a clear attempt to protect and entrench the role of the father as completing the nuclear family. However, recent developments suggest that this legal preference for the nuclear family is subject to clear emerging cracks.
\end{abstract}

Keywords: $\quad \mathrm{n} / \mathrm{a}$

\section{INTRODUCTION}

An infertile married woman separates from her husband and decides, together with a new male partner, to undergo artificial insemination using an embryo created via the sperm of a donor. Before the embryo is implanted, her new relationship breaks down and she begins an affair with a third man, with whom she intermittently cohabits. Using the embryo and relying on the formal consents supplied at the time it was created, she becomes pregnant. When her child is born which, if any, of these men has a claim to be recognised as its father? And on what values and intuitions should we draw in answering this question? More specifically: what significance can we attribute to the woman's marital status; to the fact of her (non) cohabitation; to her current relationship status; to the intention of any one or more of these men to create a child or to act as a social father; to one man's genetic links with the child; and to the fact that the sperm was obtained from an anonymous donor via a clinic? Should our answer be different if a man with a claim to be recognised as the child's father dies before the embryo is created or implanted or before the child is born? And does it make any difference if any one of these putative fathers is a female to male transsexual, whose birth certificate reflects the fact that he was born awoman? ${ }_{1}$ One thing well demonstrated by this scenario is the ability of reproductive technologies (RTs) to confuse and disrupt our understandings of parenthood.2 My starting point is that these disruptive possibilities endow the regulation of RTs with an important potential for study that has not escaped the attention of those who have taken them as a focal point for thinking 
aboutmotherhood, 3 but which has received far less attention with regard to fatherhood. Notably, in determining who should enjoy the legal status, rights and responsibilities of parents in complex reproductive situations, many values that might otherwise remain un stated are necessarily rendered explicit and hence open to criticism, contestation and analysis. As one commentator has put it:

\begin{abstract}
Modern reproductive techniques subdivide what was previously unitary. Various stages of the biological process can now be severed, allowing specific impaired aspects of the procreative process to be replaced by workable substitutes. As a result more than two persons can now be biologically involved in a given instance of reproduction. Furthermore, because processes that previously were bundled can now be separated, procreation can be depersonalized: biological reproduction can be separated from the social and physical context of interpersonal intimacy. Whenever subdivision occurs, choices emerge. Developments in reproductive technology have created new biological and social options that in turn challenge old assumptions and pose new dilemmas for legal doctrine and policy.4
\end{abstract}

Where 'choices emerge' in the legal arena, they are typically accompanied by published deliberations such as the documentation surrounding public consultations, green and white papers, parliamentary debates, statutes and court judgments. As such, the legal regulation of RTs emerges as an extremely significant resource through which we can trace the values and assumptions which underpin our views regarding fathers and their role within the family. Such is the task of the present study. I believe it timely for three reasons.

First, while discussion of the legal status, responsibilities and rights of fathers has a long history, in recent years western societies have witnessed a heightening of concern about the extent to which families need fathers, what kinds of fathers these should be and what rights they should enjoy.5 Fathers' rights campaigners have contributed to this concern, storming into the spotlight with a series of high profile stunts designed to focus popular attention on their demands for greater recognition. Law has enjoyed an important role in these protests, serving as a focal point (and, increasingly, a target) for broader political frustrations, 6 playing a central role inmediating disputes, and operating as a significant, symbolic, state-sanctioned discourse of the scope of paternal rights and responsibilities. Secondly, the question of what it means to be a father in the context of RTs is nothing if not topical, often serving as a focal point for the articulation of the broader cultural anxieties regarding the role of fathers noted above. By way of example, take the somewhat apocalyptic language used in the introduction to a Radio 4 discussion programme dealing with the topic of the founding of a new infertility treatment services clinic which aimed to market its services particularly to single and lesbian women:

It's taken ten thousand generations but men have finally become dispensable. A fertility clinic opened in Bristol this week aimed mainly at lesbians and single women . . . [and] called, chillingly, as it seems to me, Man Not Included. Now that machines have made our strength superfluous, our aggression has become a problem not a protection and even our most basic fertilising function has become superfluous, what's left for us? In a blink of time's eye, women have achieved social, financial and now sexual independence. Is man finally redundant? And if so, what's the future for man - sorry - womankind?7

The Human Fertilisation and Embryology Act 1990 ('the 1990 Act'), which regulates this area of medical practice, has provoked numerous controversies since its inception, many of which have concerned paternal status, rights and obligations and most of which have been widely reported in the popular media. The issue of whether 
children born of sperm donation should have the right to know the identity of their genetic fathers has generated much debate. The question of whether a genetic father can be registered on a birth certificate as the father of a child conceived after his death via stored sperm has recently been addressed both by Parliament and the courts. And a series of disputes concerning men's rights and obligations in assisted conception contexts have occupied our judiciary.8 Given that the 1990 Act is currently under review, with reform of its provisions seeming probable, a coherent overview and critical analysis of these developments is both timely and potentially extremely fruitful.s

Thirdly, there is little work on reproductive technologies which takes fatherhood as its central focus.10 While each of these developments has provoked public discussion, media scrutiny and academic commentary, there has been little attempt to consider them together to provide an overview of their combined significance in terms of how we think about fatherhood. This is perhaps partly due to an accepted orthodoxy within modern family law, which holds that the child must be the focal point of our analysis, and partly due to the fact that many of those who have attempted a gendered analysis of parenthood in the context of RTs have been feminist authors concerned to understand the impact of various practices onwomen. ${ }_{11}$ As such, it seems tome that there is scope for a study which is focussed on fathers. This is not intended to imply that children and women are unimportant but merely to recognise that fathers are important too and that approaching a set of problems from a different angle may yield new insights.

In what follows, I offer a close analysis of a number of legal developments in this area in order to reach two closely connected conclusions. First, it is clear that the law regulating RTs attributes great importance to fatherhood. I aim to show, however, that legal recognition of fathers is often grounded primarily in deep rooted beliefs in the symbolic importance of fathers rather than, as might be assumed, in more practical concerns with ensuring the presence of a social father.

Secondly, I argue that whilst a belief in the importance of fatherhood is broadly shared, the ways in which this status is understood and entrenched are visibly shifting. The 1990 Act can be read as a strong moral statement of the importance of the nuclear family and the imperative that each child should have one (and only one) father and mother. However, below I trace clear signs of emerging cracks in the vision underpinning the statute and an increasing openness to the idea that it can be in the best interests of a child for more than one man to share some claim to recognition as its father. As such, I argue that the clear preference for the nuclear family which was woven into the fabric of the 1990 Act is beginning to unravel. Given that the starting point for my study is a statute passed in 1990, this suggests an extremely rapid and radical evolution in understandings of the role of fathers which underpin the regulation of RTs. This evolution is significant in its own terms but, further, I would argue that a focus on the regulation of RTs may also be useful in providing a discrete and bounded example through which we can trace shifts and trends which are more broadly characteristic of understandings of fatherhood in the wider family law context. Before going further, however, I need to provide both some general context to the arguments which follow and some more detail regarding the 1990 Act, which provides the specific legal backdrop to the particular developments discussed below.

\section{The Family Law Context: Fragmenting Families}

The last thirty years have witnessed major demographic shifts in family and living arrangements and these changes have had a particularly marked impact on men's role as fathers. In particular, marriage and parenthood have been increasingly 
separated, with a significant rise in cohabitation, divorce, lone and step-parenting.12 Simpson et al write:

Fundamental shifts in gender relations and the changing economic order ofwestern societies have re-configured the nuclear family and associated patterns of domestic organisation which hitherto revolved around a male bread-winner and household head. Divorce and separation, in particular, have resulted in a profound dislocation of fathers in relation to their children ... Once the social, emotional and economic foundations of the nuclear family begin to shake, fathers typically find themselves parenting at a distance, or not at all.13

This process, described by Smart and Neale as a 'fragmentation' of families, relies above all on a fragmentation of fatherhood. Following the breakdown of a relationship, children are overwhelmingly likely to live with their genetic mother. Men who do retain parental roles and responsibilities will thus do so whilst living in a different household, possibly sharing the role of social father with the mother's new partner.14 This suggests a widespread sub-division of fatherhood, albeit one which may be less marked and radical than that possible in the context of the complex RT scenarios of the kind suggested above.

Evolution of the principles of family law over the same period is striking. In the 1970 s and 1980s, family law, policy and practice were significantly influenced by psychological theories which propounded a child's need for a single psychological parent.15'As a general rule, this translated into practices designed to sustain and strengthen a child's relationship with the custodial parent (invariably the mother) after divorce, and to protect any reconstituted nuclear family that she might seek to build with a new male partner.16 As such, the emphasis was firmly on protecting the family unit in which the child was living against outside challenge. More recently, however, the trend has been towards recognising genetic fathers' continued responsibility for their children and the enduring importance of children's relationships with both genetic parents. ${ }_{17}$ Smart and Neale have suggested that, within this legal context, divorce has come to mean not so much the end of marriage, as the start of a set of relationships based on genetic parenthood.18 And, where the mother begins a relationship with another man who takes on (some aspects of ) the role of social father, then this will obviously mean that children have contact with two potential father figures. In the light of these trends, as another commentator has put it, increasingly the question facing the courts will be not 'whether to prefer the genetic or the social parent but how to accommodate both on the assumption that they both have distinctive contributions to make to the life of the child'.19

Further, the fragmentation of fatherhood is by no means uniquely a fact of postseparation parenting. A desire to involve unmarried fathers in the lives of their genetic children is clear even when the men concerned have hitherto had little or no relationship with their children. For example, writing with regard to the growth of paternity testing, Jane Fortin has described a shift in the courts' approach away from what she describes as the 'gooseberry bush' approach, which held that provided a child had a stable home, it didn't much matter 'who she called daddy'.20 Today, when dealing with applications for paternity testing, the courts seem less concerned to protect the nuclear family from outside challenge and more convinced that a child needs to know the truth about her origins. Again, in this context, the courts recognise that these two considerations are not necessarily in conflict.21 Consequently, recent years have witnessed a far greater openness to requests for the ordering of paternity tests, even when this will introduce a father figure outside of the nuclear family within 
which a child is being raised, and even when the mother and her husband or current partner strongly oppose the test.

Greater recognition of unmarried fathers, including in circumstances where the children's mother is in a relationship with a different man who is fulfilling the role of social father, is also strongly in evidence in the context of disputes over contact and parental responsibility orders. In deciding whether to grant parental responsibility orders, the courts will consider whether the father has shown commitment

and attachment to the child and his reasons for seeking the order.22 While the paramount consideration remains the welfare of the child,23 it seems that courts are generally increasingly disposed to finding that this mandates the award of a PRO to the unmarried father.24 Similarly, the courts now operate on the basis of what Fortin has described as an apparently impregnable presumption that children will benefit from contact with a non-resident father.25 The existence of a new husband who is actively engaged in the role of social father will not in itself offer a reason for a contact order to be refused. These shifts in domestic law are supported by a burgeoning international human rights jurisprudence accepting the importance of the link between an unmarried father and his child.26

A final and even clearer example of the acceptance of the fragmentation of fatherhood ${ }^{\wedge}$ and parenthood more generally ${ }^{\wedge}$ can be seen in the evolution of adoption law and practice.27 Until the late 1970s, adoption practice was largely predicated on an exclusive model which involved complete transfer of generally illegitimate babies from the birth family to the adopters to form a new nuclear family. The effect of an adoption order was completely to sever a child's relationship with her genetic parents and to 'transplant' her into a new family. Modern practice and legislation, however, aims to support an inclusive model. This accepts that it will not necessarily be disruptive of the stability of a child's new home for the child to remain in contact with birth parents and that such contact is likely to be in a child's best interests. This approach is particularly clear in the new Adoption and Children Act 2002.28

The social context sketched above suggests a number of major shifts and a clear fragmentation of the nuclear family. In the context of adoption, this may involve the breaking of links with the birth mother. However, with this exception, the fault line in the fragmentation of families tends to lie between the unit of mother and children on the one side and the father on the other. Whilst my opening case study demonstrates the extent of the possibilities for fragmentation of the father role in the context of RTs, the broader social context sketched above shows that the fragmentation of fatherhood is already common in the context of natural reproduction, albeit not in such dramatic forms. What is also clear from the discussion above is that a greatly increased openness to recognising the significance of the roles played by a number of adults in a child's life has become increasingly central to family law over the last thirty years.

Family law has displayed considerable Flexibility in responding to the fragmentation of fatherhood. The issue of 'who is the father?' can be broken down into a series of narrower legal questions such as: who should be named on the birth certificate; who should enjoy contact rights and parental responsibility; and who should be liable financially to maintain the child? Modern family law has made very clear that the same man's name need not be given in answer to every question. As such, it is possible that the term 'father' may confuse through conflating distinct legal concepts. An attempt at clarification has been provided by Andrew Bainham, who suggests a useful tripartite distinction between parentage, a genetic relationship which will typically convey legal parenthood, the ongoing legal status as a parent, and parental responsibility, which involves the legal powers and duties necessary to perform those activities associated with social parenting. 29 In this study, I will use the term 
'fatherhood' as denoting the specifically male equivalent to Bainham's generic 'parenthood', 'father' as a man who enjoys that status, and 'genetic father' when talking specifically about parentage. 30 However, unlike Bainham, my concern is not with assisting the development of clarity and consistency within the law. Rather, my aim is to tease out the principles and assumptions that underlie the vision of men's role within the family as it has been developed in one specific area of law over the last fifteen years. I am less concerned with the normative question of which rights and responsibilities should be allocated to specific individuals, than I am with uncovering the values underpinning a decision that a given man is worthy of recognition as a 'father' or should be granted certain paternal rights or responsibilities.

\section{The Human Fertilisation and Embryology Act (1990)}

The more specific legal backdrop to the discussion which follows is provided by the Human Fertilisation and Embryology Act 1990 (the 1990 Act). One leading commentator has noted that the Act reflects more than anything a desire to protect a particular model of parenting, notably that of 'heterosexual, preferably married, parents.' ${ }_{31}$ As such, the 1990 Act might be thought to sit rather uneasily with the evolving family law context described above and, arguably, to have been anachronistic even at the time it was passed, reflecting a vision of the nuclear family which was already subject to sustained challenge on a number of fronts.

The 1990 Act establishes a regulatory regime, overseen by the Human Fertilisation and Embryology Authority (HFEA), for embryo research and for those infertility treatment services which involve creation of embryos outside of a woman's body and/or use of any gametes other than her own and those of her partner. A number of provisions of the 1990 Act are of particular interest for current purposes. First, the Act requires clinics to consider a child's welfare when deciding whom to accept for treatment, explicitly directing that account be taken of that child's need for a father. Secondly, the 1990 Act contains 'status provisions', determining who should be treated as the parents of children conceived via infertility treatment services. Thirdly, one aspect of the status provisions, concerning whether a child desired by a couple together but conceived after the death of the husband/partner should be deemed legally fatherless, has provoked particular attention both in the courts and in Parliament. Finally, the issue of whether children born of donor insemination (DI) should have access to information about their genetic origins has also provoked substantial debate, litigation and statutory reform. Each of these developments is addressed below.32

\section{Section 13(5): Child Welfare and the Need for a Father}

Probably the single provision of the 1990 Act which has generated most critical commentary is section 13(5), which provides that:

A woman shall not be provided with treatment services unless account has been taken of the welfare of any child who may be born as a result of the treatment (including the need of that child for a father), and of any other child who may be affected by the birth.33

The inclusion of the consideration of the need for a father was introduced in an amendment put forward by Conservative MP, David Wilshire and passed by 226 to 174 votes. It followed the narrow failure in the House of Lords of a more strongly worded amendment, which would have made treatment of unmarried women a criminal offence. 34 
Section 13(5) has been extensively studied, provoking both empirical studies charting the way in which it is applied in practice and more theoretical work assessing what it says about our attitudes towards appropriate mothering.35 But despite the substantial literature on section 13(5), what has remained largely unscrutinised is precisely what the posited 'need of that child for a father' actually means. It is clear that the section is not providing for the need for a genetic father: as Lee and Morgan dryly note, the section is 'not making special provision for parthenogenesis'. 36 In an early commentary, Gillian Douglas takes the section as 'presumably meaning a man who will fulfil the social role of father.37'Butwhether this presumption is correct and, if so, what is meant by 'the social role of father' in this context and why such a figure is important remain largely unexplored. Is the perceived need for social fathers to ensure the presence of a second hands-on carer? If so, is the need just for any two carers to be present, or are fathers necessary because they provide an essentially male style of parenting and in what way is this distinctive? Is the aim to ensure financial provision for children? Or were fathers deemed important rather for their symbolic role of completing the nuclear family?

In the Parliamentary debates that preceded the introduction of the1990 Act, the desirability of protecting the nuclear family is generally assumed, with MPs dividing only on how far it is legitimate to intervene to enforce this preferred model over other possible living arrangements. Nonetheless, three major grounds for asserting the importance of fathers can be discerned. First and prominent, is the need for a father as financial provider. The debates occurred at a time of widespread, media-fuelled concern about increasing social security expenditure on single parent families, with the Child Support Act 1991 under contemporaneous discussion. 38 As such, it is perhaps not surprising that financial issues were clearly on the minds of members of both Houses of Parliament. The following comment from the Earl of Lauderdale is typical:

To allow and encourage by state provision ${ }^{\wedge}$ it is at the taxpayers' expense ultimately $\wedge$ begetting of children into what are designed to be one-parent families does not make sense as regards serious sociological responsibility. 39

Secondly, the importance of fathers as hands on carers is also discussed, albeit less frequently than might be expected, with Lady Saltoun commending the inestimable benefit of a father's loving care' 40 and presenting a distinctly male model of parenting, with fathers important for the healthy psychological development of children of both sexes into the good husbands, wives, mothers and fathers of tomorrow:

Children learn primarily from example, by copying what they see. It is by example that a boy learns how to be a responsible husband and father and how to treat his own children in turn. It is by example that a girl learns how to be a wife, from seeing how her mother cares for her father. The father is enormously important, if only as a role model. 41

Thirdly, however, by far the clearest message to emerge from the debates is a strong moral assertion of the marital unit as the only acceptable forum in which to raise children. This unit is seen as the only sure start in life for children, and its decline is credited with causing much that is wrong in society.42 The importance of providing a 'stable' base for children is frequently asserted, with 'stability' standing as shorthand for heterosexualmaritalmonogamy.43 As Gillian Douglas notes, the proposers of amendments to the Human Fertilisation and Embryology Bill in the House of Lords were overwhelmingly concerned with preventing women with dubious sexual attitudes from having children, yet seemingly indifferent to others who might be deemed unsuitable as parents. 44 
Even those speakers who are reluctant to confine child bearing to the marital unit, are often convinced that it must remain the preserve of the stable, co-habiting heterosexual couple. In an intervention which seems rather poignant in the light of recent events, David Blunkett argues:

People have an absolute right to be themselves, to reject contact with men or to shun any physical contact with them. That is their choice. But that is not the same as accepting that there is some automatic or inalienable right to child bearing. Child bearing is not a right. It is part of the unfathomable life force. That is why man and woman together must take responsibility for the well-being and love of the child. 45

The underlying anxiety that 'people' (which, given the context, clearly means women) are attempting to 'reject contact with men' also provides an interesting insight into the concerns of some parliamentarians. The worry here was that which was shortly to grip the country regarding so-called 'virgin births': were women who had never had sex with a man really to be helped to conceive children? 46

A close reading of the debates, then, might suggest that parliamentarians were less concerned with the need to ensure a financial provider or hands-on (male) carer than they were with the symbolic value of ensuring children were only born into (quasi) marital units.47 Of course, the importance accorded to marriage might also reflect parliamentarians' belief that this would ensure a father's presence for the reasons given above: financial provision and a second carer who could bring specifically male attributes to bear. There are two compelling reasons for doubting this, however.

First, if the need really was for financial provision or two carers, then there is no reason to discriminate between homosexual and heterosexual couples. If what is required is at least one carer and one breadwinner, the gender of the parties should make no difference. In the entire course of the debates, no parliamentarian makes this point. Likewise, the furore regarding 'virgin births' was specifically concerned with women being able to have children when they were not in a relationship with a man. No distinction was made between single women and those in lesbian relationships.48

Secondly, that fatherhood's perceived importance lies primarily in its symbolic function of completing the nuclear family is emphasised by the privileged place accorded to widows within the debates. If the need for the father was rooted in the desire for a breadwinner or male hands-on carer, then widows should provoke the same concerns as other single parents. But in numerous interventions, parliamentarians make favourable mention of widows, seeking either to explain why their disapproval of single parents is not intended to include criticism of widows' ability as mothers (the conservatives), or as examples which demonstrate the possibility of good single parent mothering and thus the need for treatment services not to be restricted to married couples (the liberals). One MP goes so far as to recommend the possible therapeutic value to a widow of conceiving a pregnancy with the sperm of her deceased husband, with the lack of a father for the resulting children seen as a mere technicality:

A widow whose husband had left her some sperm may better come to terms with the loss of her husband by having the child that they both wanted and she still wants. The fact that she has lost her husband should not be a technical reason for preventing her from having treatment ... a widow should not feel that she should terminate her pregnancy because she will be left as a single mother.49

Widows thus emerge as a special, deserving category of woman and provide clear indication that it is not single parent families per se, but the intentional creation of children outside of a heterosexual (ideally marital) union which is the key source of concern. I will return to this point shortly. 
This brief reading of the debates around section 13(5) can offer two major insights. First, unsurprisingly, while a number of different justifications are offered for the need for a father, it was generally accepted that fathers are important. Secondly, while a number of factors underpin this belief, the most significant of these is the symbolic need for a father figure to complete the nuclear family. This is grounded in the view that the creation of children outside of a (quasi)marital relationship is morally wrong. Section 13(5) is best conceptualised, then, in terms of a refusal of single motherhood, a desire to link women to men, and an attempt to entrench the nuclear family. 50

It is important to recall at this juncture that the 1990 Act does allow for the possibility of children who will be legally fatherless: clinics need only 'consider' a child's need for a father, not ensure that a suitable one is available. This might suggest a challenge to the nuclear family model, but the challenge should not be overstated. After all, the amendment proposing to make treatment of anyone other than married couples a criminal offence, had only narrowly failed in the House of Lords. The current section 13(5) was designed as a compromise measure to achieve similar limitations on access to treatment services in a less rigid way. In their authoritative guide to the 1990 Act, Morgan and Lee are clear that the policy underlying the legislation was actively to discourage treatment for those infertile people who live outside the umbrella of the nuclear family. ${ }_{51}$ Any reproductive freedom offered by this provision is left firmly within the hands of clinicians who will act as gatekeepers to the provision of infertility treatment services, and many clinics refuse treatment to those not in stable heterosexual relationships. As such, while there is a small caveat in the 1990 Act's protection of the nuclear family, it is no more than that.

Such an understanding of section 13(5) is implicit in the HFEA Chair's recent condemnation of the provision as discriminating against single women and lesbian couples. Suzi Leather notes that: '[it] is absolutely clear if you think about the changes in society and the different ways that families can be constituted that it is anachronistic for the law to include the statement about the child's need for a

father.' 53 The same sentiment is implicit in a Department of Health memorandum submitted to the ongoing Select Committee inquiry into the workings of the 1990 Act, which notes that the current law is: 'framed in terms of heterosexual couples' and may need to be changed better to recognise the wider range of people who seek and receive assisted reproduction services in the $21_{\text {st }}$ century.' 54

\section{Diane Blood, Deceased Fathers and the Privileging of Widows}

The Right to Use Her Husband's Sperm. The tremendous sympathy extended to widows in the parliamentary debates was also evident in responses to one of the most famous challenges to the 1990 Act and the powers of the HFEA.55 Diane Blood had married in 1991. Towards the end of 1994 she and her husband, Stephen, decided to try to start a family. Before this could happen, however, Stephen contracted meningitis and lapsed into a coma. Shortly before he died, Diane Blood asked for samples of his sperm to be collected by electro-ejaculation for use at a later date. The clinic complied but, unfortunately for Blood, the 1990 Act lays down stringent consent requirements for the posthumous use of gametes which were not met in her case.56 As such, the HFEA refused leave for the sperm to be used by Blood in the UK or exported for use in a Belgian clinic. Blood successfully challenged this latter aspect of the HFEA's decision, convincing the Court of Appeal that the HFEA had not properly considered the implications of European Community law, which protected her right to obtain medical services in another Member State. Reviewing her case in the light of this strong judicial steer, the HFEA gave permission for Blood to take the sperm to Belgium, where she has since used it to conceive two sons. 
For current purposes, the clear sympathy for the widowed Mrs Blood expressed in the courts, media and, later, Parliament is of particular interest. This seemed to hinge securely on her explicit portrayal of herself as a married woman, with the spectre of her husband very much present throughout the case. Morgan and Lee capture this well in their compelling commentary on the case:

Diane Blood fought to continue the interests which she and her husband had in forming a family; the desire to prolong family interests. Stephen Blood is very much present throughout the legal argument. His widow (as she markedly styles herself ) Diane Blood, comes to represent something enigmatic and anomalous, as far as reproduction and sexuality is concerned. What she does, she does patently in the name of the father . . .57

Given the antipathy often displayed towards single mothers (ostensibly on the basis of their children's need for a father), and the fact that the fertile Mrs Blood was attempting to use techniques portrayed as a last resort for those unable to conceive, one might have expected some criticism of her actions.58 But the general approbation of Mrs Blood seemed to stem not just from sympathy for her loss, but also from the fact that she was viewed as a respectable married woman, epitomising all the attributes of a good mother: committed to her husband, pious, serene, and gentle.59 Central to Diane Blood's story were ideas of what her husband would have wanted and of their joint desire for a child.

The sympathy of the courts is also clear. Sir Stephen Brown P, hearing the case in the Family Division of the High Court, notes:

My heart goes out to this applicant who wishes to preserve an essential part of her late beloved husband. The refusal to permit her so to do is for her in the nature of a double bereavement.60

In upholding her right to travel to receive treatment services in another Member State, the Court of Appeal makes short shrift of the HFEA's argument that Blood was free to travel, just not to export illegally obtained sperm. The Court notes that her desire to have a child is very firmly located in her marital relationship:

where a wife wishes to receive artificial insemination services using sperm of her late husband, it is artificial to treat the refusal of permission to export the sperm as not withholding the provision of fertilisation treatment in another member state. From a functional point of view, the ability to provide those services is not only substantially impeded but made impossible.61

Again, the symbolism of the father is crucial. The deceased Stephen Blood clearly cannot offer shared childcare or financial support. He is nonetheless very much present throughout the case as vital legitimation for his wife's desire for a child.

The Right for Deceased Fathers to be Named on Birth Certificates. Following her success in the Court of Appeal, treatment in Belgium and eventual delivery of two sons, Ms Blood returned to the courts to challenge a further provision of the 1990 Act: that where sperm (or an embryo created using such sperm) was used after the sperm provider's death, that man was not to be treated as the father of the child.62 Her contention was that denial of the right to have their father's name on their birth certificates breached her children's human rights. This argument was accepted by both the Government and the High Court, the latter making one of the very few declarations of incompatibility issued since the coming into force of the Human Rights Act 1998. 
The Human Fertilisation and Embryology (Deceased Fathers) Act (2003) has now been passed to remedy this problem. The Act is symbolic in both intention and effect. It gives force to Sheila McLean's recommendation, made in a report commissioned after the first Blood case, that children born in these circumstances should have a symbolic acknowledgement of their father on their birth certificates.63 It provides that, in certain circumstances, a man may be registered as the father of a child conceived after his death using his sperm or an embryo created with his sperm. Further, it enables a man to be so registered where a child is conceived after his death using an embryo created from donor sperm before his death, where the couple had embarked on infertility treatment services together. Unusually, the legislation has retroactive operation.64 Finally, it is noteworthy that recognition of paternity is to have no legal force in terms of succession and will not give the child any legal status or rights which would prevent the winding up of a man's estate.

The reform is also suggestive of another broad trend in the way we think about fatherhood. While the provisions of the 1990 Act reflect a deeply entrenched belief that each child should have no more than one legal father,65 the 2003 Act reflects a growing willingness to recognise that children may have attachments to more than one father figure, and that this is not necessarily to their detriment. In this regard, it is particularly interesting to note the volte-face of Lady Warnock who came out as a strong supporter of Blood, despite earlier strong pronouncements against posthumous conceptions.66 Warnock explains her change of heart partly in terms of the removal of the legal implications of recognising fatherhood, stating that the Committee of Inquiry which she chaired had been concerned by the potential problems of inheritance and the tying up of the father's estate or the settling of succession to a title. She claims that the 'admirable' idea of separating birth registration from the legal implications of paternity had never occurred to them.67 But, intriguingly, Warnock also comments on the possibility of disruption to other family relationships:

The committee of inquiry was fairly strongly opposed to the use of assisted conception to bring about the birth of a posthumous child largely on the grounds of the possible psychological damage that might be caused if, for example, a widow who had remarried and had other children decided to use her first husband's sperm and to have a child by that husband after all.68

Warnock now dismisses this possibility as 'rather fanciful'. But it is nonetheless interesting that the need to record the father's name as a simple matter of recording 'the historical truth'69 now outweighs the kind of concern that had prevailed less than fifteen years previously. For the architect of the 1990 regime, recognition of paternity is no longer seen as a threat to future family arrangements. Rather, it is accepted that a child can have a legally recognised link to more than one 'father', with this construed as a benefit rather than a potentially harmful, disruptive and confusing state of affairs.

\section{Sections 27 and 28: the Status Provisions}

The initial refusal of the status of legal father to men who had died before their sperm or embryos were used was part of a broader raft of provisions setting out who should be treated as mother and father of a child born following infertility treatment services, collectively referred to as the status provisions. The attribution of the status of mother proves relatively straightforward. It takes section 27 of the 1990 Act just over one hundred words to provide that, excluding in the case of adoption, the birth mother and no other is to be treated as the legal mother of the child. This is true whether the egg used to conceive the pregnancy was the woman's own and regardless of the 
provisions of any surrogacy arrangement that shemay havemade. In theUK, legalmotherhood is thus a status firmly grounded in gestation.70

The legal designation of father is substantially more complicated, taking almost six times as many words. In brief, where a child results from those RTs covered by the 1990 Act, under section 28(2), the woman's husband will be the father unless it can be shown that he did not consent to the treatment.71As such, marriage retains a privileged place as the preferredway of attributing paternity. If no father exists by virtue of section 28(2), an unmarried man will be deemed the legal father under section 28(3) where treatment services were provided for him and the woman together.72 Unmarried male partners can thus gain the same parental rights as married men, though without the presumption of consent that occurs in marriage.73 Where someone is treated as a father by virtue of either of these provisions, no other man is to be treated as the father of the child. Where sperm is obtained through a licensed clinic, a sperm donor is not to be treated as the legal father and, as such, where treatment services are provided for a single woman or awoman in a same sex relationship, the resulting child will be legally fatherless.74

The elaborate definition of legal 'fatherhood' contained in section 28 might, in itself, be taken as suggesting an attempt to contain the perceived disruptive potential of RTs in relation to paternity, legitimacy and contact rights.75 The dense language of the provision suggests an attempt to think through the various complex possibilities raised by $R T$ s and, in each potential factual situation, to allocate fatherhood status in such away as tomost clearly approximate the nuclear family. As John Dewar notes: '[t]he definition of paternity ... reflects, more than anything, the type of parents whom the state is prepared to reproduce through the provision of fertility services: namely, the two parent, heterosexual, preferably married, parents'.76

Again, the symbolism of fatherhood and replication of the nuclear family is crucial: each child should ideally have a father who is married to her mother or, failing that, a father who is committed to the mother and intending to create a child with her. And, as was seen in the above review of section 13(5), it was envisaged that only in exceptional circumstances would a woman be allowed to make use of infertility treatment services without a father figure being available. Finally, the section displays a clear intention that a child can and should have only one legal father. A married woman, who seeks treatment services together with a different male partner, cannot succeed in securing two legal fathers for her children.

Thus, in the status provisions, Parliament attempted to foresee every possible reproductive scenario and to provide for the resulting family arrangements to conform as closely as possible to a nuclear family model. Inevitably, however, such foresight had its limits and the status provisions have raised some interesting problem cases for the UK courts.77 I turn now to those decisions dealing with whether a particular man can be considered a child's father within the meaning of section 28 , focussing on two recent cases. It is my contention that, whilst bound to operate within the limits of the status provisions and their entrenchment of the nuclear family norm, a certain degree of judicial creativity has allowed for recognition of some more complex family forms relying, notably, on a fragmentation of fatherhood.

\section{$\operatorname{Re} \mathrm{R}, \operatorname{Re} \mathrm{D}_{78}$}

Ms D and Mr B together sought treatment services involving the use of donor semen. When they separated, D continued the treatment with her new partner, Mr S, not telling the clinic about the change in relationship and relying on the formal consent previously supplied by $B$. When $D$ gave birth, B sought parental responsibility and contact orders with respect to the child, R.79 In the first instance hearing, all parties conceded that B was R's legal father. Not called on to find on that issue, Hedley $\mathrm{J}$ 
ordered indirect contact and for $B$ to be given photographs of $R$, reasoning that he would be an important stabilizing member of her family. He directed himself that the following factors were significant:

\begin{abstract}
First, the child depends upon her mother for her nurture and welfare. Secondly, that The mother is mentally and emotionally fragile and, I am satisfied, genuinely would be unable to cope with direct contact. Thirdly, this child is likely to encounter serious issues in understanding her background and for that will be dependent on a mother in whom I do not have confidence to face up to those issues; I think there is a real risk that the issue will be shelved and even that the child will initially, at least, be misled. Fourthly there is no basis on which this child could understand who Mr B was or why he was being introduced into her life and, whilst that is sometimes an issue with a putative father, it is exacerbated in this case by the unusual biological background. Fifthly I am satisfied that Mr B is genuine in his desire for contact and parental responsibility and may well have an important role in helping the child to come to terms with her origins; moreover, I am not satisfied that I can rely on Mr S (from whom I have not heard) to provide a father-figure indefinitely or, indeed, to be allowed by the mother to do so.80
\end{abstract}

Hedley J's views on why B will be necessary to R's welfare are expressed largely in terms of her need to knowher own identity,81 and in confidence in B (and not in D) to provide this information effectively. The judge assumes that at least one man must be present in a fathering role and he is not persuaded that Mr S will be so 'indefinitely'. As such, B's claim for a greater presence in R's life would be strengthened by the absence of S. Significantly, however, the presence of $S$ does not serve as a bar to B's involvement.

Hedley $\mathrm{J}$ adjourned B's application for parental responsibility, noting that this was likely to be granted if he maintained his commitment to indirect contact for the next couple of years. B was to be treated as the father for all purposes, being in the same position as a natural father, despite the lack of any biological link with $R$. This decision gave rise to two separate appeals. In the first of these, brought by $B$ regarding the extent of contact granted to him, the Court of Appeal was not prepared to overturn Hedley J's ruling. It commended Hedley $\mathrm{J}$ on the fact that he:

rightly took the view that the fact of biological parentage could be relevant to the welfare of a child ... . [and] that it was beneficial to the child that there should be a potential relationship with the man deemed to be the child's father because he had more confidence that the father would be able to deal in due course with the delicate issue of the circumstances of her conception and birth than the mother. 82

In the second appeal, brought by Don the issue of paternity, the Court found that B could not be considered the legal father under section 28 and, as such, $R$ would be legally fatherless. This, however, did not affect the earlier rulings regarding contact.83

Three observations can be made here. First, both courts clearly take a dim view of D's actions in deliberately misleading the clinic. Speculatively, it might be suggested that the granting of rights to B might thus be seen as a way of imposing appropriate and responsible (male) control over her, the need for such control being further mandated by her mental and emotional fragility.84 The fact that the durability of the mother's relationship with $S$ cannot be proven, might be seen not just in terms of a lack of a suitable father figure for $R$ but also as leaving $D$ without a man to rein in her excesses. Secondly, Re R demonstrates the weight attached to genetic factors and the growing currency of a 'right to genetic truth', though this does not play out in any straight forward way. While $B$ does not share a genetic link with $R$, he can claim some limited rights because of the role he can play in explaining her genetic origins. Unusually, then, the rights he is granted are grounded in his role of provider of 
information. Thirdly, neither court appears overly concerned by the possibility that introducing B into R's life is liable to cause confusion or to disrupt the family unit which her mother claims to be building with $\mathrm{S}$. Hedley $\mathrm{J}$ does note that the disappearance of $S$, leaving the child without a social father, might strengthen B's case for direct contact and that he is not convinced by the adequacy of $S$ as a father figure, again reinforcing the perceived need for each child to have a father.85 But beyond this, the judge's desire to foster contact between $B$ and $R$ suggests that the existence of more than one party with some claim to be considered a child's father is not necessarily a bad thing. The benefits gained by a child knowing something about its genetic origins outweigh any potential negative impact. 86

\section{The Leeds Teaching Hospitals NHS Trust v MrA, Mrs A and Others87}

This final point is born out even more clearly by the case of Leeds. Mr and Mrs A had consented to the creation of embryos using only their own gametes and to the embryos' use only for their own treatment or for research. Unfortunately, Mrs A's eggs were erroneously fertilised with the sperm of Mr B, who was undergoing the same treatment at the same clinic with his wife. Mrs A subsequently gave birth to twins. Although the As were both white, it was clear that the twins were of mixed race. DNA tests proved that Mr B was their genetic father.

All parties accepted that the As would raise the children, but $\mathrm{Mr} A$ and $\mathrm{Mr} B$ both sought declarations of legal paternity. The Court found that Mr A could not be considered the legal father, as section 28(2) did not apply to his situation. He had not consented to the placing in his wife of the embryos in question, which were fundamentally different from those he had intended should be created. Neither could section 28(3) apply: 'treatment together' involves a joint enterprise and this was undermined by Mr A's lack of consent to the use of another man's sperm. 88

This judgment turns in large part on a careful reading of a statute, the drafters of which surely did not have in mind this unusual set of facts. Whilst the Court's finding that such a fundamental mistake undermines Mr A's consent is an entirely plausible one, it was not the only interpretation available to it.89 Finding what exactly was included in Mr A's consent and what kind of mistake would undermine it, clearly allowed scope for some discretion. Indeed, due regard to parliamentary intention might have suggested a finding in Mr A's favour, given the clear desire to protect the sanctity of the nuclear family described above. This makes the broad principles upon which the Court draws in reaching its verdict all the more interesting. As has been noted above, the 1990 Act is characterised by a concerted effort to entrench the nuclear family, ensuring that each child should have one (and only one) mother and father. However, in Leeds, our then most senior family law judge was clearly of the view that attributing legal fatherhood to Mr B was not liable to disrupt the nuclear family.

The effect of the decision of the court ... does not create any greater difficulty for the twins than the unfortunate circumstances surrounding their conception and birth. Although they lose the immediate certainty of the irrebuttable presumption that $\mathrm{Mr} \mathrm{A}$ is their legal father, they will remain within a loving, stable and secure home. They also retain the great advantage of preserving the reality of their paternal identity ... To refuse to recognise $\mathrm{Mr} \mathrm{B}$ as their biological father is to distort the truth about which some day the twins will have to learn through knowledge of their paternal identity. The requirement to preserve the truth will not adversely affect their immediate welfare nor their welfare throughout their childhood. It does not impede the cementing of the permanent relationship of each of them with $\mathrm{Mr} \mathrm{A}$.

Thus while the 'reality' of paternal identity reflects a view of that status as premised on genetic links, it is recognised that a family structure can be 'stable and secure' and in 
the best interests of the twins, even where it includes more than two 'parents'. This resonates with Hedley J's assertion in Re D that R could benefit From contact with two 'fathers'. Dame Butler-Sloss, P. continues:

Through no fault of theirs, [the twins] have been born children of mixed race by a mistake which cannot be rectified. Their biological mother and their biological

father are not married and cannot marry. They may not be able during their childhood to for many relationship with their biological father. They have inherited two cultures but, in reality, can only gain real benefit from one during their childhood. Of all the parties who have undoubtedly suffered from this mistake, the twins, who at present know nothing of it, have had their human rights most obviously and seriously infringed.91

This passage is noteworthy for a number of reasons, including the assumption that the twins have 'suffered' from the mistake first by virtue of the fact that their biological parents are not married (by implication, the ideal state of affairs) and secondly because forming a relationship with their genetic father may be impossible (even though this is a broadly accepted reality for the many children born of DI). There also appears to be a troubling implication that to be born mixed race is a misfortune, which the twins have suffered 'through no fault of theirs'. Had the twins not been mixed race, would the Court of Appeal have decided this case in the same way? While we cannot know the answer to this question, the idea that the twins 'have inherited two cultures 'might not be compelling had all four 'parents' shared a common ethnic background.92 Considerations of race appear thinly veiled here in the suggestion that 'culture' is genetically inherited and that where one derives from two distinct cultures, understanding of both is desirable.93

It is also interesting to note the popular response to this decision. By and large, more progressive commentators have criticised it for failing to value social parenting over the 'mere' genetic link, thereby identifying the wrong man as the 'real' father. Juliet Tizzard's editorial in the weekly newsletter of the Progress Educational Trust is typical.

[I]n this case, where legal paternity is placed next to biological paternity, the genetic connection seems to be regarded as more important than the social one ... But what is the reality of their paternal identity? The twins' biological father is $\mathrm{Mr}^{\mathrm{B}}{ }^{\wedge}$ this much is indisputable. But declaring him to be the legal father too begins to make him look like the 'real father'. But Mr A intended to be their father. He was there at conception (even though he wasn't responsible for it), during the pregnancy, at the birth and, more importantly, he has been their father every day since their birth and intends to be their father until the day he dies. Shouldn't that be regarded as the 'reality' of their paternal identity? 94

This reading of Leeds accepts the historically entrenched parameters of decision making in this area: that the search must be for the candidate (and for one candidate alone)who will best fit the role of 'real father'. This sets the scene for a debate as to whether 'real' fathering is about genetics or social parenting.

Such a reading might locate the judicial response to Leeds within a broader shift towards the geneticisation of fatherhood with RTs implicated in fostering a genetic, rather than social, understanding of that status. It seems to me, however, that the picture presented by Leeds is both substantially more complicated and far more interesting than simply involving a dispute about which of the two men is the 'real' father. The courts here are explicitly prepared to countenance more than one father (and two parents) in the twins' lives, and to assert this as a positive, serving to foster awareness of their cultural background, and thereby enrich their familial situation. Rather than seeing Leeds solely within a shift away from social towards genetic 
fatherhood, I would argue that it is thus better contextualised within a movement towards recognising a fragmentation of fatherhood, with a number of different parental figures potentially important for different reasons.

Finally, it is worth noting that Leeds illustrates an important difference in how we think about motherhood and fatherhood. The fragmentation of parenthood into social and genetic roles is a profoundly gendered phenomenon.95 If Leeds had involved the implantation of embryos created from the gametes of Mrs B and Mr A, or even the gametes of both Mr and Mrs B, Mrs A would still have enjoyed an unequivocal legal claim to be considered the mother of any resulting children.96 While motherhood is legally firmly rooted in gestation, fatherhood is an altogether more complex and fragmented status.

The above reading suggests that Leeds and $R e D / R e R$ reflect the same shift evidenced in the second Blood case and the Human Fertilisation and Embryology (Deceased Fathers) Act 2003.This trend is against the 1990 Act's clear attempt to impose the model of the nuclear family towards an acceptance that knowledge of, and contact with, more than one father may be in a child's best interests. One father is better than none but, in some circumstances, it is now accepted that to may be better than one.

\section{Donor Insemination and Anonymity}

Dame Butler-Sloss P.'s clear assertion of the importance of genetic information in Leeds resonates with a growing recognition of the interests of children born by donor insemination (DI) to know the identity of their genetic fathers, supported by a clear trend in the jurisprudence of the European Court of Human Rights.97 Again the idea that a child might benefit from knowledge of, or contact with, a genetic father who is not also her social father represents a significant challenge to the assumptions reflected in the 1990 Act, which was clear in its desire to protect the nuclear family. The Act provides that the mother's husband or partner would be the legal father, with the donor remaining anonymous and playing no role in his genetic child's life. Donor anonymity was adopted as a strategy by those who

wish[ed] both to accept gamete donation and to resolve some of the problems it presents to notions of the 'ordinary family'. It helps to preserve as many as possible of the conventional features of the family by setting a barrier around the unit.98

More recently, however, following much popular debate, media interest and public consultation, the Government has announced a change in the law: on reaching the age of eighteen, children born as a result of sperm, eggs or embryos donated after April 2005 will acquire the right to know the identity of the donors.99

Debates regarding donor anonymity have frequently reflected the terms used by Tizzard above, accepting a binary divide between social and genetic fathers with disagreement focussed on the question of which should count as 'real' fathers. Such an understanding has underpinned some commentators' condemnation of this reform as part of a general shift towards geneticisation.100 Yet, without denying the increased importance attributed to genetic ties, I would argue that this needs to be located within a growing belief that knowledge of one's genetic paternity is not necessarily disruptive to one's social family and relationship with one's social parents. This is illustrated by the case of Rose, which preceded the announcement of reform.101

\section{Rose and Another v Secretary of State for Health and Another 102}

Both of the claimants in Rose were conceived via DI. JR, born in 1972, had been unable to discover any information about her genetic father and the records possibly 
containing such information had been destroyed. The only information available regarding EM's genetic father related to height, build, hair and eye colour and blood group. The claimants requested the provision of non-identifying information and, where possible, identifying information regarding anonymous donors (JR) and nonidentifying information and establishment of a contact register (EM).

In seeking judicial review of the Government's refusal to provide this information, the claimants relied on Articles 8 and 14 of the European Convention of Human Rights, asserting discrimination relative to adoptees, and also between donor offspring born before the 1990 Act came into force, and those born thereafter. Their application was granted. The Court found that they were seeking to obtain information that went to the very heart of their identity and make up as human beings. As such, their article 8 rights were clearly engaged. Respect for privacy and family life had been interpreted by the European Court to incorporate the concept of personal identity, and this included the right to obtain information about a biological parent.103

The disclosure of information sought in Rose is presented as necessary not to provide a genetic father who can replace the social father, but rather to give a further source of information about one's own genetic identity. JRtells the Court:

these genetic connections are very important to me, socially, emotionally, medically, and even spiritually. . . [N]on-identifying information will assist me in forming a fuller sense of self or identity and answer questions that I have been asking for a long time ... With the revelation of my donor conception I am now unable to complete medical history forms ... I do not know about half of my ethnicity or racial identity.104

Again, there is a strong assertion of the symbolic importance of fatherhood, with the need for knowledge of one's genetic parentage expressed not just in terms of the practicalities of medical information, but as a 'spiritual' need. The judge accepts this claim, noting that: '[h]ere what the claimants are trying to obtain is information about their biological fathers, something that goes to the very heart of their identity, and to their make up as people.'105

The second complainant, EM, is still a young child and it is her mother who is asserting her right to this information, explaining: 'I believe that secrecy can be very destructive to individuals and to families and I would like to be able to protect our daughter as much as I can from this ... If in the future our daughter wanted to make contact with the donor then we would completely support her and help her in this.' 106 The provision of information regarding her genetic father here emerges as important in cementing EM's relationship with her social parents. Honesty is an important value within that relationship and ignorance of her genetic father's identity will thus undermine the social family. Contacting the donor would be a matter for the family unit as a whole, in no way undermining the affective bonds upon which it is predicated. While, as a matter of empirical fact, it seems that most heterosexual couples have chosen not to reveal much detail regarding the circumstance of conception to their DI child, 107 this case clearly suggests that some parents intend to be more open and do not view this as a threat to their own familial stability. Rather, sharing information about origins and giving a child the choice to have more information about the identity of the donor is presented as best for the well being of the whole family. And it also clearly suggests that the courts are receptive to this understanding of disclosure, an understanding which is supported by a growing body of research suggesting that keeping a child's genetic origins secret is harmful to the family.108

Contrary to those who have suggested that allowing access to donor registrations is a move towards a more geneticised vision of fatherhood, I would again suggest that what is happening here is actually something rather more complex. It seems tome that this development can best be understood as part of a fracturing of 
fatherhood into its constituent parts, a correlative proliferation of men with some claim to be considered 'a father', and a recognition that knowledge of one's genetic father may not disrupt one's relationship with one's social father; that social and genetic ties can coexist harmoniously. Thus, in Rose, the courts simply recognise a fact long known to them in other family law contexts: that various ways of grounding some paternal rights, obligations or status may be advanced on behalf of different men. For JM's mother, at least, the ability to be honest about JM's genetic father is a way of cementing her own family structure. Access to one's genetic father, then, is clearly not perceived to be in competition with protection of the social family. Rather the former complements, and can even strengthen, the latter.109

\section{CONCLUSION}

At a time when the status, rights and responsibilities of fatherhood are so fiercely contested, the possibilities opened by RTs' subdivision of that status and rendering explicit of choices and judgments as to who can lay claim to it are of particular interest. As has been seen above, Parliament and the courts have been forced to deliberate on the issue of who should count as a father in a variety of novel reproductive scenarios. In determining the appropriate response to the social and ethical dilemmas created by RTs, they have been called upon to develop a social and moral vision of families and men's role within them. This vision can provide us with an interesting, if inevitably partial, series of snapshots of broader social understandings of fatherhood.

The above analysis of the regulation of RTs over the last fifteen years suggests a widely shared belief in the importance of fatherhood grounded primarily, though by no means exclusively, in fatherhood's perceived symbolic value in completing the nuclear family. This was particularly evident in Parliamentary debates regarding section 13(5), the status provisions, and the introduction of the Human Fertilisation and Embryology (Deceased Fathers) Act 2003. Popular responses to various aspects of the 1990 Act have often been similarly reliant on the nuclear family form, focussing on the need to identify the 'real' father of a child and differing only with regard to who best merits that title. Implicit in such appeals to authenticity is an assumption of exclusivity: each child can have only one 'real' father, with claims asserted on behalf of any other man implicitly denigrated to the lesser status of pretence.

Yet despite the clear attempt made in the 1990 Act to protect and entrench the nuclear family, subsequent developments provide a significantly more complex, nuanced and messy picture. I join other writers in recognising the increased priority accorded to genetics in some of these developments. The growing currency of a 'right to genetic truth' was clearly visible in the discussion of the removal of donor anonymity, in the introduction of the Human Fertilisation and Embryology (Deceased Fathers) Act (2003) and in the section 28 cases discussed above. It is equally in evidence in the development of law and practice relating to adoption and paternity testing. ${ }_{110}$ However, I have argued against the idea that a genetic vision of fatherhood is superseding other ways of grounding fatherhood. It has been my contention that the acceptance of a right to 'genetic truth' has developed, at least in part, because of a growing belief that such knowledge is unlikely to dislodge the role of the social father. Most strongly, it has been suggested that knowledge of one's genetic father can even serve to cement and protect relationships within one's social family (as claimed by EM's parents in Rose). And while the 1990 Act has entrenched the idea that we should have just one legal mother and father, the section 28 cases considered above revealed the courts as willing to introduce further father figures outside the nuclear family. In these cases, the child's interest in the 'genetic truth' is understood not just as a need for information, but also as grounding claims to contact with one's genitors. In Leeds, the courts were willing to accept that contact with a number of 'parents' would 
not damage the As' nuclear family and would best serve child welfare. Likewise in Re $R$, contact with Mr B was not seen as undermining Ms D's attempts to build and protect a new nuclear family structure with Mr S. As such, the currency accorded to a right to 'genetic truth' is at least partly grounded in an acceptance of the fragmentation of fatherhood.

Byway of conclusion, I would like to offer some brief thoughts on three issues: why the developments described above have taken place; whether they are to be welcomed; and, finally, what the above analysis might offer to the ongoing review of the 1990 Act.

First, why is it that the need to ensure that each child has one, and only one, father seems less pressing now than it did fifteen years ago to the drafters of the 1990 Act? It seems tome that a number of factors are important. First, most of the developments discussed above have focussed on the requirements of known, concrete individuals. 111 It is possible that the desire to entrench the nuclear family may have seemed more attractive to Parliament, called upon to consider the issues largely in the abstract, than it does to the courts confronted with known individuals fighting to maintain or to establish familial relationships. Courts used to dealing with the complexity and messiness of human relationships on a day to day basis may be more accustomed to the idea of protecting and entrenching a child's relationship with a number of adults. Secondly, Janet Dolgin has argued that as the disruptive potential of RTs becomes apparent, 'traditional understandings of the family as a universe grounded in inexorable truth begin to fall apart' and, as a consequence, 'some profoundly conservative impulse at the center of culture asserts itself in opposition.' 112 If this is true, then as the possibilities offered by RTs become more familiar then they should also become less threatening with the result that this 'conservative impulse' to rein in their potential may prove less compelling. Looking at the regulation of RTs in the context of the broader developments set out in the introduction, it might seem that the 1990 Act's strict adherence to the model of the nuclear family was an anachronism even fifteen years ago, being significantly out of step with broader trends in social reality, family law and policy. Perhaps what has changed, then, is that RTs are not quite as frightening today as they were in the 1980s. Familiarity may sometimes breed acceptance. Finally, those same trends already in evidence in 1990 have gained further momentum over the last fifteen years. It is possible that the world has simply moved on, with the image of the family fossilised in the 1990 Act rendered ever more out of step with social reality. As such, it might be argued that the developments in the law regulating $\mathrm{RTs}$ represent nothing more than the attempt to revise and interpret the 1990 Act in the light of the evolving principles and values utilised in the broader family law context.

Whatever the relationship to the broader legal context, the challenges to the nuclear family model so painstakingly crafted in the 1990 Act are profound. What are we to make of them? A detailed normative evaluation of these developments is clearly beyond the scope of this paper, but two brief points are worth making. First, recognising that a number of adults may play important roles in a child's life, rather than insisting rigidly on the need for just one mother and one father who share all parental rights and duties, might appear a welcome recognition of the reality of current family arrangements. Such moves would seem to fit with the recommendations of those who have argued for the need to focus on family practices rather than the status of residing within a pre-given structure: on 'doing' rather than 'being' family.113 Secondly, however, while these parental rights are extended outside the nuclear family, in the developments discussed above they are granted primarily to those who can most closely approximate some part of the traditional role prescribed for the father within it (husband, genitor and breadwinner).114 As such, while these developments 
suggest cracks in the nuclear family model, these cracks follow rather familiar fault lines. For instance, they show more men acquiring more parental rights at a time when these same rights are routinely denied to lesbian non-gestational mothers. 115 While a deceased father who has no genetic relationship with a child can now be named on a birth certificate, a living and actively parenting lesbian co-mother cannot, even if she has planned the conception with her partner and supported her throughout IVF, the resulting pregnancy and birth. This remains true even where she contributed the egg used to conceive their child and is thus the genetic mother.

Finally, what of the future? It is to be hoped that any review of the1990Act will look carefully at how parenthood is constructed within it, in away which is cognisant of a number of other recent legal developments which suggest a rather more flexible approach. Specifically, the Civil Partnership Act 2004 has recently provided for greater recognition of same-sex couples and the Adoption and Children Act 2002 provides for joint adoption by unmarried couples, including those of the same sex.116 In the light of these reforms, it would be strange if Parliament did not see fit to delete the requirement of consideration of a child's 'need for a father' under section 13(5) and to extend the wording of section 28(3) so that a lesbian couple who make use of donor insemination to fulfil a joint enterprise to create a child can both be recognised as her legal parents. The Act might also easily be amended to allow unmarried (including same-sex) couples who make use of surrogacy arrangements to benefit from the fasttrack adoption procedures currently only available to married couples.117 Such reforms to the 1990 Act would be consistent with a general tendency within family law gradually to roll out the privileges which adhere to the marital union to those other family forms which most closely resemble it. How best to address the more radical questions suggested by a fragmentation of parenthood in the context of both RTs and 'natural' reproduction must remain beyond the scope of this paper.118 